\title{
Effects of terrain slope on water distribution and application uniformity for sprinkler irrigation
}

\author{
Lin Zhang ${ }^{1}$, Xin Hui ${ }^{2}$, Junying Chen ${ }^{2 *}$ \\ (1. Institute of Soil and Water Conservation, Northwest A\&F University, Yangling 712100, Shaanxi, China; \\ 2. College of Water Resources and Architectural Engineering, Northwest A\&F University, Yangling 712100, Shaanxi, China)
}

\begin{abstract}
In order to provide practical parameters for sprinkler irrigation system design on slope land, the effects of terrain slope on water distribution, sprinkler throw radius and water application uniformity were analyzed for the Rainbird LF1200 sprinkler. The results show that, the water distribution curve is roughly "heart-shape" on slope land, and the water has the trend of focusing on the upslope with the increase of the slope. Throw radius decreases for the upslope and increases for the downslope as the slope increases. For the convenience of sprinkler irrigation system design on slope land, a formula for computing throw radius on slope land was put forward by the theoretical derivation, and it was verified by the experimenta data. The impact of sprinkler pressure and spacing on CU for slope land is more significant than that for flat ground. Under the experimental condition, no significant change is found regarding the influence of terrain slope on water application uniformity at the confidence level of 95\%. Taking irrigation quality and economy into account, the Rainbird LF1200 sprinkler should be operated at the manufactures' recommended pressure, rather than low pressure, with sprinkler spacing from $8 \mathrm{~m} \times 8 \mathrm{~m}$ to $10 \mathrm{~m} \times 10 \mathrm{~m}$ below the slope of 0.15 in practice.
\end{abstract}

Keywords: sprinkler irrigation, slope land, water distribution, water application uniformity, throw radius DOI: $10.25165 /$ j.ijabe.20181103.2901

Citation: Zhang L, Hui X, Chen J Y. Effects of terrain slope on water distribution and application uniformity for sprinkler irrigation. Int J Agric \& Biol Eng, 2018; 11(3): 120-125

\section{Introduction}

Water application uniformity is a performance goal and central design for sprinkler irrigation system ${ }^{[1-3]}$, although absolute uniformity of applied water is never obtained in irrigation practice. The uniformity of applied water depends on sprinkler head and nozzle (size, type, angle, and pressure), distribution system hydraulics (sprinkler spacing, lateral spacing, riser height, and hydraulic losses in pipes and fittings), weather conditions (magnitude and direction of wind speed), field topography, management practices, and so on ${ }^{[4-7]}$. Poor water application uniformity results uneven soil moisture replenishment, which has a significantly negative impact on crop growth.

There are many studies of water distribution patterns and application uniformity for sprinkler irrigation, including experimental investigations and numerical simulation works ${ }^{[8-10]}$. The assessment of water application uniformity in solid set sprinkler systems was conducted by Siosemarde ${ }^{[11]}$. He found that water application uniformity increased as sprinkler spacing decreased. The acceptable values of water application uniformity were obtained from low sprinkler spacing, and pressure variations had a negative impact on uniformity. To obtain water distribution with medium-sized sprinklers, some single radial leg tests were carried out with/without wind, respectively, and the influence of speed and direction of wind, operating pressure, and sprinkler

Received date: 2016-10-09 Accepted date: 2018-03-16

Biographies: Lin Zhang, PhD, Associate Professor, research interests: theory and equipment of water saving irrigation, Email: zl0211wy@163.com; Xin Hui, MS, research interests: sprinkler irrigation, Email: xin0821h@163.com.

*Corresponding author: Junying Chen, $\mathrm{PhD}$, Associate Professor, research interests: new technology of water saving irrigation. No.26 Xinong Road, Yangling, Shaanxi 712100, China. Tel: 02987082902, Fax: 02987082901, Email: cjyrose@126.com spacing on water distribution were studied by Tarjuelo ${ }^{[12,13]}$. The results showed that the speed of wind has obvious negative influence on water application uniformity. Larger sprinkler spacing results lower water application uniformity. Louie et al. found that field precipitation variations are mainly due to management factors $^{[14]}$. Mateos and Zhang et al. assessed sprinkler irrigation water application uniformity in the whole-field ${ }^{[6,15]}$.

Also, many simulation works were conducted on sprinkler irrigation uniformity in the past several decades. Fukui et al. put forward basic equations and procedures for ballistic simulation of sprinkler irrigation ${ }^{[16]}$. Li et al. proposed a method for simulating droplet motion using modified mathematical models of droplet dynamics and evaporation, and also developed the corresponding software. Based on the given radial leg water distribution data of a single sprinkler, the software can predict water distribution of a single sprinkler or a solid-set sprinkler irrigation system under various sprinkler spacing and different environmental parameters ${ }^{[17]}$. Faria et al. and Siyanda et al. simulated the impact of wind on water distribution patterns ${ }^{[18,19]}$. Mantovani et al. and $\mathrm{Li}$ et al. analyzed the influence of sprinkler irrigation uniformity on crop yield ${ }^{[20,21]}$

Previous research is very useful for improving sprinkler irrigation quality. However, these studies mainly focused on flat ground. For sloping farmland, the ability of soil water retention is poor and the traditional surface irrigation method is inappropriate due to variable topography, so crops are highly susceptible to suffer from drought. Sloping farmland covers about $1 / 4$ of the total cultivated area in China, and sprinkler irrigation is increasingly being used for sloping farmland because of its good adaptability to complex terrain. However, there is a lack of sprinkler irrigation research on sloping farmland. Water distribution for sprinkler irrigation on sloping farmland is very different from that on flat 
ground because of terrain slope, resulting in poor application uniformity. In order to provide practical parameters for sprinkler irrigation system design on slope land, the Rainbird LF1200 sprinkler, which is commonly used in agricultural irrigation, was selected to study the effect of terrain slope on water distribution, sprinkler throw radius and combinational water application uniformity.

\section{Materials and methods}

\subsection{Experimental setup}

The experiment was conducted at Irrigation Hydraulics Laboratory, Northwest A\&F University, China. The experimental apparatus consisted of sprinkler, height adjustable bracket and steel channel, catch-can, pressure transducer, pump, stainless steel water tank, PVC pipes, valves and other necessary test equipments, as shown in Figure 1.

The Rainbird LF1200 sprinkler (Figure 2), which is very commonly used in agricultural irrigation, was selected for the study. The nozzle is $2.18 \mathrm{~mm}$, the jet angle is $17^{\circ}$, and the recommended operating pressure range is from $210 \mathrm{kPa}$ to $410 \mathrm{kPa}$ for the sprinkler.

The experimental slope surface was artificially constructed by 60 height adjustable brackets and 48 steel channels with the length of $3.0 \mathrm{~m}$ and width of $0.15 \mathrm{~m}$. There were totally 12 rows of brackets, and the length of each row was $12 \mathrm{~m}$ with 5 brackets in a row and $3 \mathrm{~m}$ bracket spacing. The horizontal distance between the two rows was $1 \mathrm{~m}$. The height of the brackets in each row has been calculated according to the experimental slope, and the actual height was adjusted according to the calculation. Every 4 steel channels were put on the 5 brackets in each row to make an experimental slope surface with a length of $12 \mathrm{~m}$ and width of about $11 \mathrm{~m}$. Catch-cans were white plastic containers with the opening diameter of $10.6 \mathrm{~cm}$ and height of $14.0 \mathrm{~cm}$, and they were placed in the steel channels and arranged by grid. The grid size on the ground projection was $1 \mathrm{~m} \times 1 \mathrm{~m}$. There were 12 rows and 11 catch-cans on each row, for a total of 121 catch-cans.

The sprinkler was installed vertically at the bottom and top of the left of the slope surface, respectively. Riser height was $30 \mathrm{~cm}$ according to the manufacturer recommendation. At the given operating pressure, the sprinkler was firstly installed at the top of the slope, and water distribution for the downslope was recorded. After a one-hour test, the sprinkler was installed at the bottom of the slope, and water distribution for the upslope was recorded at exactly the same operating pressure. The combination of water distribution for the downslope and upslope was water distribution for the single sprinkler on the slope.

A sprinkler screen was constructed to prevent water from splashing on the electronic instruments. The pressure transducer was a Xi' an Xinmin model CYB, with a range from 0 to $500 \mathrm{kPa}$ at the $\pm 0.1 \%$ accuracy. The pressure transducer wrapped in plastic bag was installed at the inlet of the sprinkler and connected to a data logger. The pressure was recorded at 5 -sec intervals by the data logger during each one-hour sprinkler test, and the average pressure was calculated for each test.

A two-dimensional video distrometer produced by Joanneum Research (Austria) was placed at the end of the sprinkler throw radius to measure the droplet landing angle when the sprinkler was tested on flat ground. The droplet landing angle was used for calculating the sprinkler range on various slopes herein. The horizontal velocity and vertical velocity of a single drop were computed directly by the two-dimensional video distrometer.
Therefore the landing angle can be obtained through inverse tangent of the ratio of vertical velocity and horizontal velocity.

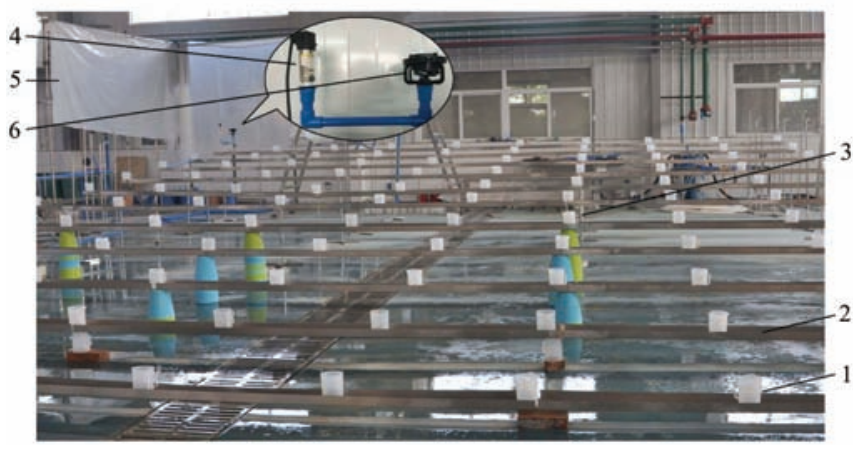

1.Rain gauge 2. Stainless steel groove 3. Height adjustable bracket 4. Pressure sensor 5. Retaining plastic 6. Sprinkler

Figure 1 Experimental setup for the sprinkler water distribution on the artificial slope land

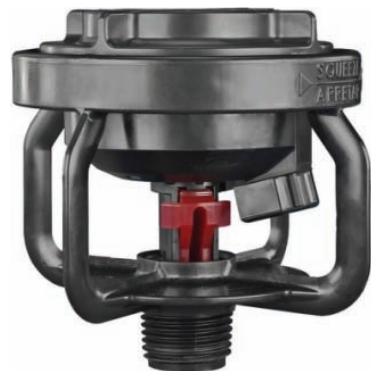

Figure 2 Sprinkler used in the experiment

\subsection{Experimental design}

Experimental factors were sprinkler operating pressure and slope. Sprinkler operating pressure has 5 levels, which are $100 \mathrm{kPa}, 150 \mathrm{kPa}, 200 \mathrm{kPa}, 300 \mathrm{kPa}$ and $400 \mathrm{kPa}$, respectively. Slope has 4 levels: $0,0.05,0.10$ and 0.15 , respectively. There were totally 20 trials, and each trial included two one-hour tests: water distribution measured for upslope and downslope respectively.

The pump was used to provide the sprinkler the desired operating pressure. By setting a manual valve before starting data collection, the desired operating pressure was produced for each test. The long tape was used to measure sprinkler range, and the graduated cylinders were used to measure water volume from each catch-can after each test. Catch-cans must be emptied and dried before being returned to the appropriate location in the steel channels for the next test.

The Christiansen Uniformity Coefficient (CU) is the most commonly used indicator which assesses sprinkler irrigation water application uniformity in agriculture. $\mathrm{CU}$ can be calculated by Equation (1):

$$
\mathrm{CU}=100\left[1-\frac{\sum_{j=1}^{n}\left|V_{j}-\bar{V}\right|}{\sum_{j=1}^{n} V_{j}}\right]
$$

where, $V_{j}$ is the measured volume from an individual catch-can; and $\bar{V}$ is the average measured volume of all catch-cans. Also, volumes can be replaced by depths in Equation (1).

\section{Results and discussion}

\subsection{Sprinkler throw radius on various slopes}

3.1.1 Effect of slope on throw radius

Throw radius is an important hydraulic parameter for sprinkler. 
It plays a key role in the determination of sprinkler spacing and lateral spacing. Throw radius on various slopes for upslope and downslope is shown in Table 1. Data in Table 1 showed a general pattern that increases of slope leads to decreases of throw radius for upslope, and increases of throw radius for downslope increases the difference between throw radius for downslope and upslope. Due to the effect of topography, the landing time of water jet trajectory for sprinkler irrigation on slope land is different from that on flat ground. When water sprays to the upslope direction, the landing of water jet trajectory is earlier than that for flat ground because of slope surface blocking. Greater slope results earlier landing and shorter throw radius. When water sprays to the downslope direction, the result described above is reversed.

Under the same condition of slope, the sprinkler throw radius at low pressure is shorter than that at manufacturers' recommended pressure range, and the difference between throw radius for downslope and upslope at low pressure is larger than that at the recommended pressure. The large difference between throw radius for downslope and upslope is unfavorable for water distribution overlap, as it results in poor application uniformity.

Table 1 Sprinkler throw radius on various slopes

\begin{tabular}{|c|c|c|c|c|c|}
\hline $\begin{array}{c}\text { Pressure } \\
\quad / \mathrm{kPa}\end{array}$ & \multicolumn{2}{|c|}{ Slope } & $\begin{array}{l}\text { Throw } \\
\text { radius for } \\
\text { upslope/m }\end{array}$ & $\begin{array}{l}\text { Throw radius } \\
\text { for downslope } \\
\qquad / \mathrm{m}\end{array}$ & $\begin{array}{c}\text { Difference between } \\
\text { throw radius for } \\
\text { downslope } \\
\text { and upslope/m }\end{array}$ \\
\hline \multirow{8}{*}{$\begin{array}{c}\text { Recommended } \\
\text { pressure } \\
\text { range }\end{array}$} & \multirow{4}{*}{300} & 0.00 & 10.40 & 10.40 & 0.00 \\
\hline & & 0.05 & 10.00 & 10.71 & 0.71 \\
\hline & & 0.10 & 9.60 & 11.00 & 1.40 \\
\hline & & 0.15 & 8.60 & 11.20 & 2.60 \\
\hline & \multirow{4}{*}{400} & 0.00 & 10.50 & 10.50 & 0.00 \\
\hline & & 0.05 & 10.10 & 10.81 & 0.71 \\
\hline & & 0.10 & 9.70 & 11.10 & 1.40 \\
\hline & & 0.15 & 8.80 & 11.30 & 2.50 \\
\hline \multirow{12}{*}{$\begin{array}{l}\text { Low } \\
\text { pressure } \\
\text { range }\end{array}$} & \multirow{4}{*}{100} & 0.00 & 7.00 & 7.00 & 0.00 \\
\hline & & 0.05 & 6.65 & 7.51 & 0.86 \\
\hline & & 0.10 & 6.43 & 8.42 & 1.99 \\
\hline & & 0.15 & 6.10 & 8.60 & 2.50 \\
\hline & \multirow{4}{*}{150} & 0.00 & 8.40 & 8.40 & 0.00 \\
\hline & & 0.05 & 8.05 & 9.21 & 1.16 \\
\hline & & 0.10 & 7.74 & 9.50 & 1.76 \\
\hline & & 0.15 & 6.88 & 9.61 & 2.73 \\
\hline & \multirow{4}{*}{200} & 0.00 & 9.20 & 9.20 & 0.00 \\
\hline & & 0.05 & 8.91 & 10.11 & 1.20 \\
\hline & & 0.10 & 8.64 & 10.40 & 1.76 \\
\hline & & 0.15 & 7.38 & 10.60 & 3.22 \\
\hline
\end{tabular}

\subsubsection{Calculation of throw radius on various slopes}

The design of sprinkler spacing and lateral spacing is based primarily on throw radius. For convenience of sprinkler system design, the formula for calculating throw radius on various slopes was derived. The schematic diagram of sprinkler water jet trajectory on various slopes was given in Figure 3. With other parameters (operating pressure, riser height, etc) being equal, water jet trajectory is exactly the same on various slopes. The portion of water jet trajectory closed to the surface of flat ground could be approximated to a straight line when the slope is small. That is, line $\mathrm{AE}$ or $\mathrm{EC}$ in Figure 3 is approximated to a straight line. Formulas for calculating throw radius for upslope and downslope can be derived by solving the right triangle in Figure 3 .

$$
R_{\text {upslope }}=R_{0} \cos \beta[1-\tan \beta \cot (\theta+\beta)]
$$

$$
R_{\text {downslope }}=R_{0} \cos \beta[1+\tan \beta \cot (\theta-\beta)]
$$

where, $R_{\text {upslope }}$ and $R_{\text {downslope }}$ are throw radius for upslope and downslope (m), respectively; $R_{0}$ is throw radius on flat ground (m); $\beta$ is projected angle (the angle between the projection of water jet trajectory on slope and that on level surface $\left(^{\circ}\right) ; \theta$ is droplet landing angle on flat ground $\left({ }^{\circ}\right)$.

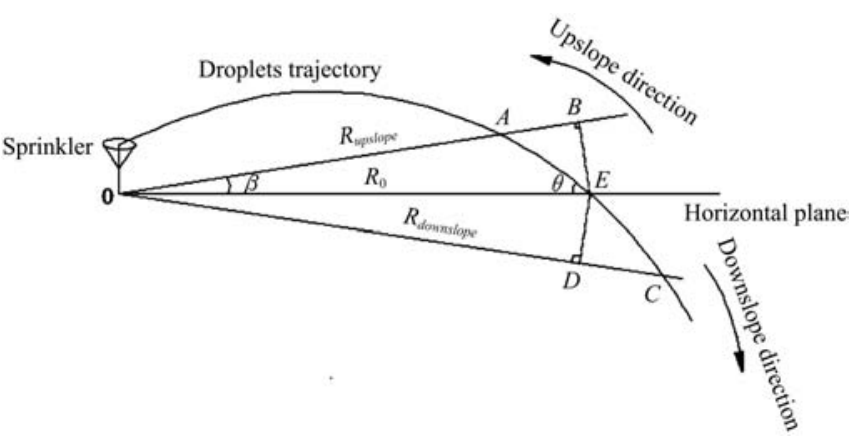

Figure 3 Schematic diagram of sprinkler water jet trajectory on various slopes

$\beta$ is related with terrain slope and the angle for sprinkler rotating on slope. It can be calculated by Equation (4):

$$
\beta= \pm \frac{180}{\pi} \arctan (i \sin \alpha)
$$

where, $i$ is terrain slope; and $\alpha$ is sprinkler rotating angle $\left({ }^{\circ}\right)$. Here, the plus and minus signs are for the $\beta$ term and specify $0 \leq \alpha \leq 180^{\circ}$ and $180^{\circ}<\alpha<360^{\circ}$ conditions, respectively.

When sprinkler operating pressure is given, $R_{0}$ and $\theta$ can be measured on flat ground. Then, throw radius can be calculated on various slopes at the given pressure using Equations (2) and (3). To verify the validity of Equations (2) and (3), the calculated values of throw radius were compared with the measured ones on various slopes. As seen in Figure 4, the difference between the calculated and measured values was within $8.5 \%$, indicating the calculated values were in good agreement with the measured ones. However, Equations (2) and (3) are unavailable for steep slopes, because they were derived based on the hypothesis that the portion of water jet trajectory closed to the surface of flat ground could be approximated to a straight line. It was seen from the results of the comparison in Figure 4 that Equations (2) and (3) are available when the slope is less than or equals to 0.15 . Generally, Equations (2) and (3) are appropriate in most cases in practice, because most sprinkler irrigation systems are never installed on very steep slopes.

\subsection{Effect of slope on water distribution for single sprinkler}

Water distribution of single sprinkler is the basic information for sprinkler irrigation system design. Figure 5 shows water distribution of single sprinkler on various slopes at the operating pressure of $300 \mathrm{kPa}$. The coordinate point $(0,0)$ is the location of the sprinkler. It was seen from Figure 5 that water distribution on slope is different from that on flat ground. Water distribution curves are approximated to be a group of concentric circles, in which the center is the sprinkler on flat ground and water application rates at the same distance from the sprinkler are almost the same. However, there is a little irregularity for water distribution curves on flat ground due to the structure of the sprinkler. The sprinkler has four brackets connecting the inlet and cap (Figure 2). In the process of sprinkler rotating, water flow from the nozzle to air is affected by the four brackets, resulting in the part of dark blue for water distribution in Figure 5a. The 
water distribution curve is similar to a "heart-shape" on slope, and the water has the trend of focusing on the upslope with the increase of the slope. At the same distance from the sprinkler, water application rate for upslope is greater than that for downslope. For example, when the slope is 0.1 and the distance from the sprinkler is $4 \mathrm{~m}$, water application rates are $0.91 \mathrm{~mm} / \mathrm{h}$ and $0.58 \mathrm{~mm} / \mathrm{h}$ for upslope and downslope, respectively. This is the result of the shorter throw radius for upslope and longer throw radius for downslope caused by terrain slope, while larger terrain slope leads to more obvious difference of wetted area between upslope and downslope. Water volume from sprinkler to unslope is the same as to downslope, so water application rate for upslope is greater than that for downslope at the same distance from the sprinkler.

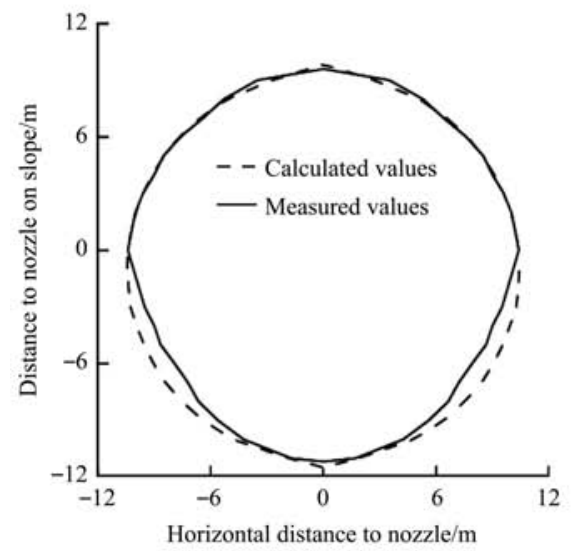

a. $i=0.05$

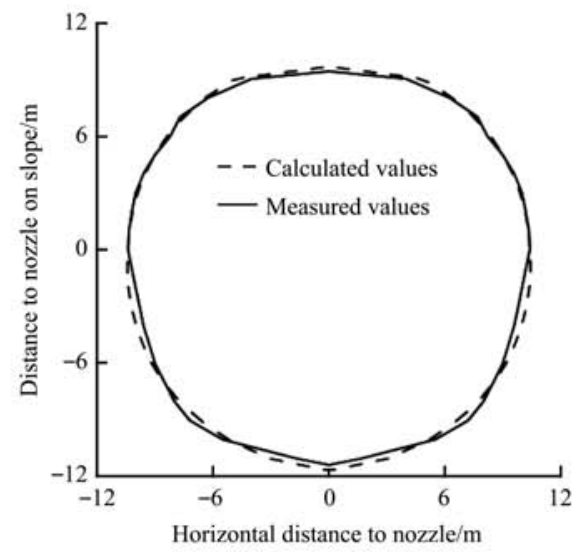

b. $i=0.10$

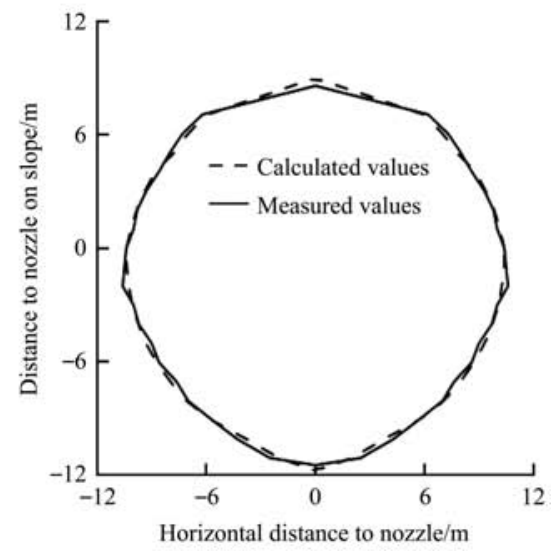

c. $i=0.15$

Figure 4 Comparison of measured and simulated values of sprinkler range

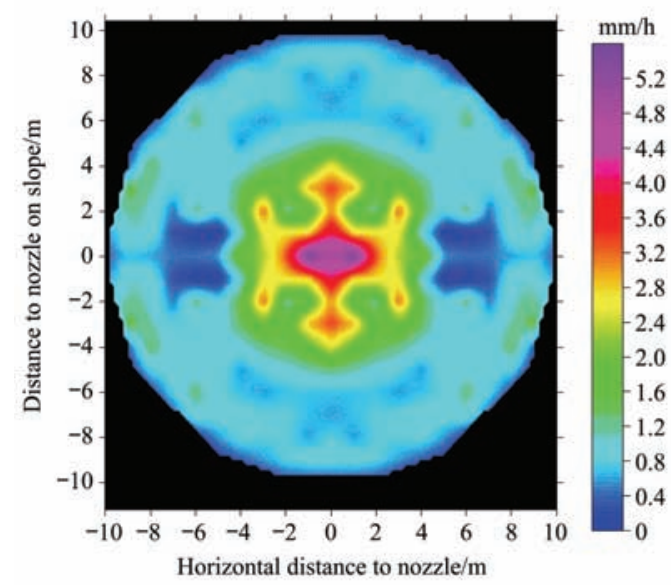

a. $i=0$

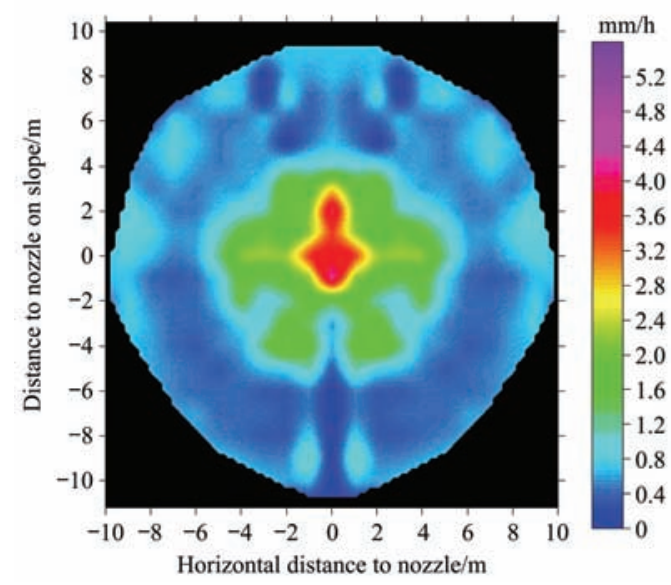

c. $i=0.10$

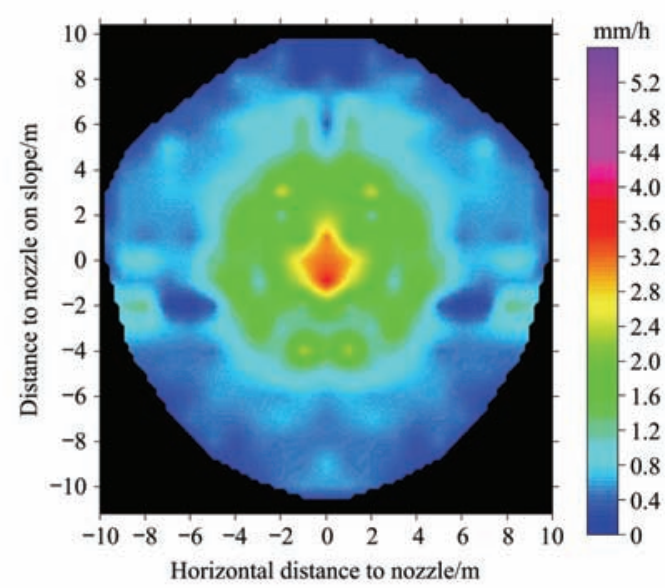

b. $i=0.05$

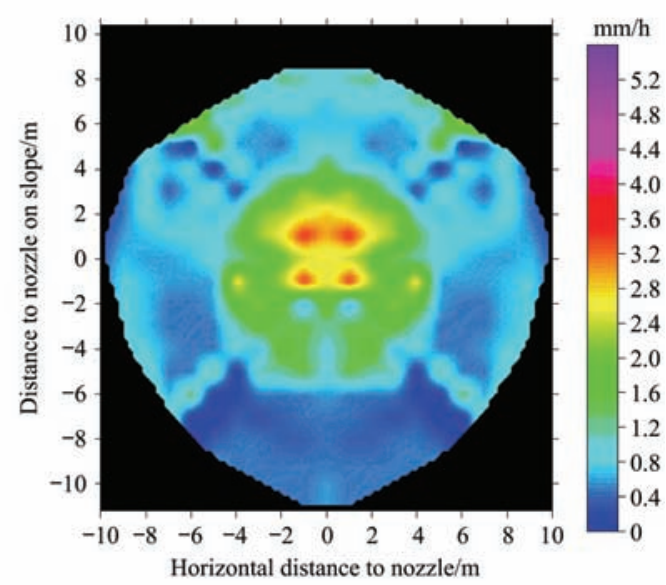

d. $i=0.15$

Figure 5 Water distribution for single sprinkler on various slopes

\subsection{Effect of slope on water application uniformity}

Water application uniformity is an important indicator for sprinkler irrigation system design. Because throw radius for the Rainbird LF1200 sprinkler operating at the recommended pressure range is about $10 \mathrm{~m}$ on flat ground, sprinkler spacing of $6 \mathrm{~m} \times 6 \mathrm{~m}$,
$8 \mathrm{~m} \times 8 \mathrm{~m}, 10 \mathrm{~m} \times 10 \mathrm{~m}$ and $12 \mathrm{~m} \times 12 \mathrm{~m}$ were selected for calculating $\mathrm{CU}$ on various slopes. The values of $\mathrm{CU}$ for various slopes are shown in Table 2. At the same pressure and sprinkler spacing, $\mathrm{CU}$ increases firstly and then decreases as the slope increases, and the value of $\mathrm{CU}$ reaches its maximum when the slope is 0.05 


\section{(Table 2).}

When sprinklers run in the recommended pressure range, $\mathrm{CU}$ is high and most $\mathrm{CU}$ values are above $80 \%$ (the minimum CU used by many designers) except for $\mathrm{CU}$ values with the sprinkler spacing of $10 \mathrm{~m} \times 10 \mathrm{~m}$ and $12 \mathrm{~m} \times 12 \mathrm{~m}$ at the pressure of $300 \mathrm{kPa}$, and $\mathrm{CU}$ values with the sprinkler spacing of $12 \mathrm{~m} \times 12 \mathrm{~m}$ at the pressure of $400 \mathrm{kPa}$. However, CU is generally low when sprinklers run at low pressure. Whatever sprinkler spacing and slope are, most values of CU are in the range of $40 \%$ to $70 \%$, which are far below $80 \%$. Only when sprinkler spacing is $6 \mathrm{~m} \times 6 \mathrm{~m}$ and the slope is less than 0.10 , the value of $\mathrm{CU}$ can reach $80 \%$ when the low pressures are $150 \mathrm{kPa}$ and $200 \mathrm{kPa}$. When sprinklers run at low pressure, the operation cost of sprinkler irrigation system are reduced. However, to meet the requirements of irrigation uniformity, sprinkler spacing should be decreased, resulting in increased initial investment of sprinkler irrigation system. Therefore, considering irrigation quality and economy, the Rainbird LF1200 sprinkler should run within the recommended pressure rather than low pressure. The recommended sprinkler spacing is from $8 \mathrm{~m} \times 8 \mathrm{~m}$ to $10 \mathrm{~m} \times 10 \mathrm{~m}$.

Table 2 Values of water application uniformity on various slopes

\begin{tabular}{|c|c|c|c|c|c|c|}
\hline \multirow{2}{*}{\multicolumn{2}{|c|}{$\begin{array}{l}\text { Pressure } \\
\quad / \mathrm{kPa}\end{array}$}} & \multirow{3}{*}{$\begin{array}{l}\text { Slope } \\
0.00\end{array}$} & \multicolumn{4}{|c|}{ Sprinkler spacing } \\
\hline & & & \multirow{2}{*}{$\frac{6 \mathrm{~m} \times 6 \mathrm{~m}}{88.3}$} & \multirow{2}{*}{$\frac{8 \mathrm{~m} \times 8 \mathrm{~m}}{83.4}$} & \multicolumn{2}{|c|}{$10 \mathrm{~m} \times 10 \mathrm{~m} 12 \mathrm{~m} \times 12 \mathrm{~m}$} \\
\hline \multirow{8}{*}{$\begin{array}{l}\text { Recommended } \\
\text { pressure } \\
\text { range }\end{array}$} & \multirow{4}{*}{300} & & & & 78.3 & 68.7 \\
\hline & & 0.05 & 89.0 & 89.4 & 81.2 & 76.2 \\
\hline & & 0.10 & 86.6 & 81.2 & 75.0 & 67.8 \\
\hline & & 0.15 & 83.1 & 82.6 & 79.3 & 70.9 \\
\hline & \multirow{4}{*}{400} & 0.00 & 89.1 & 88.9 & 81.5 & 75.9 \\
\hline & & 0.05 & 92.4 & 90.4 & 84.7 & 83.8 \\
\hline & & 0.10 & 88.0 & 90.6 & 80.7 & 78.1 \\
\hline & & 0.15 & 87.0 & 83.3 & 82.9 & 77.7 \\
\hline \multirow{12}{*}{$\begin{array}{l}\text { Low } \\
\text { Pressure } \\
\text { range }\end{array}$} & \multirow{4}{*}{100} & 0.00 & 59.9 & 52.6 & 29.2 & 25.4 \\
\hline & & 0.05 & 60.3 & 54.4 & 44.3 & 30.9 \\
\hline & & 0.10 & 74.1 & 56.4 & 45.3 & 38.7 \\
\hline & & 0.15 & 68.7 & 49.9 & 42.7 & 35.3 \\
\hline & \multirow{4}{*}{150} & 0.00 & 86.7 & 67.9 & 59.4 & 50.5 \\
\hline & & 0.05 & 83.8 & 72.8 & 62.7 & 58.1 \\
\hline & & 0.10 & 77.0 & 60.4 & 57.9 & 46.7 \\
\hline & & 0.15 & 76.4 & 55.8 & 54.6 & 48.9 \\
\hline & \multirow{4}{*}{200} & 0.00 & 87.7 & 69.5 & 70.1 & 50.6 \\
\hline & & 0.05 & 89.8 & 78.3 & 75.1 & 63.9 \\
\hline & & 0.10 & 80.1 & 71.5 & 63.4 & 53.6 \\
\hline & & 0.15 & 78.4 & 72.2 & 69.3 & 57.5 \\
\hline
\end{tabular}

Analysis of variance of the effect of each factor on CU on flat ground and slope land are shown in Table 3 and Table 4, respectively. As seen in Table 3, under the experimental condition, the effect of sprinkler pressure on $\mathrm{CU}$ is significant and the influence of sprinkler spacing on $\mathrm{CU}$ is insignificant at the confidence level of $95 \%$ for flat ground. As seen in Table 4, under the experimental condition, the effect of sprinkler pressure and spacing on $\mathrm{CU}$ is significant, and no significant change is found regarding the influence of terrain slope on $\mathrm{CU}$ at the confidence level of $95 \%$ for slope land. This comparison indicated that the impact of sprinkler pressure and spacing on $\mathrm{CU}$ for slope land is more significant than that for flat ground. At the same sprinkler pressure, water distribution for single sprinkler is different on various slopes. Thus, the effect of sprinkler spacing on $\mathrm{CU}$ becomes more obvious as slope increases. Because no significant change is found as for the influence of terrain slope on $\mathrm{CU}$, good uniformity will be achieved within a certain range of the slope if sprinkler pressure and spacing are appropriate. The slope below 0.15 is recommended for the Rainbird LF1200 sprinkler in practice.

Table 3 Analysis of variance of the effect of each factor on $\mathrm{CU}$ on flat ground

\begin{tabular}{lccccc}
\hline \multicolumn{1}{c}{ Factor } & $\begin{array}{c}\text { Sum of square } \\
\text { of deviation }\end{array}$ & $\begin{array}{c}\text { Degree of } \\
\text { freedom }\end{array}$ & $\begin{array}{c}\text { Mean square } \\
\text { deviation }\end{array}$ & $\begin{array}{c}\mathrm{F} \\
\text { value }\end{array}$ & $\begin{array}{c}\mathrm{P} \\
\text { value }\end{array}$ \\
\hline Pressure & 4323.232 & 4 & 1080.808 & 6.214 & 0.004 \\
Sprinkler spacing & 2168.880 & 3 & 722.960 & 2.428 & 0.103 \\
Error & 6932.252 & 19 & & & \\
\hline
\end{tabular}

Table 4 Analysis of variance of the effect of each factor on $\mathrm{CU}$ on slope land

\begin{tabular}{lccccc}
\hline \multicolumn{1}{c}{ Factor } & $\begin{array}{c}\text { Sum of square } \\
\text { of deviation }\end{array}$ & $\begin{array}{c}\text { Degree of } \\
\text { freedom }\end{array}$ & $\begin{array}{c}\text { Mean square } \\
\text { deviation }\end{array}$ & $\begin{array}{c}\mathrm{F} \\
\text { value }\end{array}$ & $\begin{array}{c}\mathrm{P} \\
\text { value }\end{array}$ \\
\hline Pressure & 9308.186 & 4 & 2327.046 & 23.790 & 0.000 \\
Sprinkler spacing & 3829.690 & 3 & 1276.563 & 6.584 & 0.001 \\
Slope & 318.585 & 2 & 159.293 & 0.632 & 0.535 \\
Error & 14687.990 & 59 & & & \\
\hline
\end{tabular}

\section{Conclusions}

In summary, in this study, water distribution and throw radius were measured for the Rainbird LF1200 sprinkler on various slopes. The water distribution curve is roughly "heart-shape" on slope, and the water has the trend of focusing on the upslope with the increase of the slope. Throw radius decreases for upslope and increases for downslope as the slope increases. A formula for calculating throw radius on various slopes was put forward by the theoretical derivation, and it was verified by the experimental data. The effect of each factor on water application uniformity was studied by analysis of variance, and the suitable parameters were recommended for the Rainbird LF1200 sprinkler operating on slope in practice. These results are very useful for the design of sprinkler irrigation system on slope land.

However, this study was carried out under indoor condition, thus the effect of wind on water application uniformity was not considered. In addition, the runoff cannot be considered in the sprinkler system design, although it is very difficult to avoid runoff on the ground surface for sprinkler irrigation on slope land due to the terrain slope and gravity effects. The runoff will be distributed secondly on the slope land surface, which has some effect on water distribution and water application uniformity. Therefore, the wind and runoff effects should be considered in the further research.

\section{Acknowledgements}

The authors are grateful to the financial support by National Natural Science Foundation of China (51779246, 51409244), Key Research and Development Program of Shaanxi Province (2017NY-118), Science and Technology Program of Yangling Demonstration Zone (2017NY-28), and National Science and Technology Support Program (2015BAD22B01-02).

\section{[References]}

[1] Jiang Y, Chen $\mathrm{C}$, $\mathrm{Li} \mathrm{H}$, Xiang Q J. Influences of nozzle parameters and low-pressure on jet breakup and droplet characteristics. Int J Agric \& Biol Eng, 2016; 9(4): 22-32. 
[2] Felix-Felix J R, Salinas-Tapia H, Bautista-Capetillo C, Garcia-Aragon J, Burguete J, Playan E. A modified particle tracking velocimetry technique to characterize sprinkler irrigation drops. Irrigation Science, 2017; 35(6): 515-531.

[3] Darko R O, Yuan S Q, Liu J P, Yan H F, Zhu X Y. Overview of advances in improving uniformity and water use efficiency of sprinkler irrigation. Int J Agric \& Biol Eng, 2017; 10(2): 1-15.

[4] Ouazaa S, Burguete J, Zapata N. Solid-set sprinklers irrigation of field boundaries: experiments and modeling. Irrigation Science, 2016; 34(2): 85-103.

[5] Carrion F, Sanchez-Vizcaino J, Corcoles J I, Tarjuelo J M, Moreno M A. Optimization of groundwater abstraction system and distribution pipe in pressurized irrigation systems for minimum cost. Irrigation Science, 2016; 34(2): 145-159.

[6] Zhang L, Merkley G P, Pinthong K. Assessing whole-field sprinkler irrigation application uniformity. Irrigation Science, 2013; 31(2): 87-105.

[7] Hu Y G, Zhao C, Liu P F, Amoah A E, Li P P. Sprinkler irrigation system for tea frost protection and the application effect. Int J Agric \& Biol Eng, 2016; 9(5): 17-23.

[8] Yuan S Q, Darko R O, Zhu X Y, Liu J P, Tian K. Optimization of movable irrigation system and performance assessment of distribution uniformity under varying conditions. Int J Agric \& Biol Eng, 2017; 10(1) $72-79$.

[9] Li L H, Zhang X Y, Qiao X D, Liu G M. Analysis of the decrease of center pivot sprinkling system uniformity and its impact on maize yield. Int J Agric \& Biol Eng, 2016; 9(5): 108-119.

[10] Zapata N, El Malki E H, Latorre B, Gallinat J, Citoler F J, Castillo R, et al. A simulation tool for advanced design and management of collective sprinkler-irrigated areas: a study case. Irrigation Science, 2017; 35(4): $327-345$.

[11] Siosemarde M, Byzedi M, Nodehi D A. The evaluation of water distribution uniformity in solid set sprinkler systems. Journal of Food
Agriculture and Environment, 2012; 10(2): 818-822.

[12] Tarjuelo J M, Montero J, Valiente M, Honrubia F T, Ortiz J. Irrigation uniformity with medium size sprinklers part I: Characterization of water distribution in no-wind conditions. Transaction of ASAE, 1999; 42(3): 665-675.

[13] Tarjuelo J M, Montero J, Carrión P A, Honrubia F T, Calvo M A. Irrigation uniformity with medium size sprinklers part II: Influence of wind and other factors on water distribution. Transaction of ASAE, 1999; 42(3): 677-689.

[14] Louie M J, Selker J S. Sprinkler head maintenance effects on water application uniformity. Journal of Irrigation and Drainage Engineering-ASCE, 2000; 126(3): 142-148.

[15] Mateos L. Assessing whole field uniformity of stationary sprinkler irrigation systems. Irrigation Science, 1998; 18(2): 73-81.

[16] Fukui Y, Nakanishi K, Okamura S. Computer evaluation of sprinkler irrigation uniformity. Irrigation Science, 1980; 2(1): 23-32.

[17] Li Y C, Bai G, Yan H J. Development and validation of a modified model to simulate the sprinkler water distribution. Computers and Electronics in Agriculture, 2015; 111: 38-47.

[18] Faria L C, Beskow S, Colombo A, de Oliveira H F E. Modeling of wind effects on water application uniformity of sprinkler irrigation: medium-sized sprinklers. Revista Brasileira De Engenharia Agricola E Ambiental, 2012; 16(2): 133-141.

[19] Sayyadi H, Sadraddini A A, Zadeh D F, Montero J. Artificial neural networks for simulating wind effects on sprinkler distribution patterns. Spanish Journal of Agricultural Research, 2012; 10(4): 1143-1154.

[20] Mantovani E C, Villalobos F J, Orgaz F, Fereres E. Modeling the effects of sprinkler irrigation uniformity of crop yield. Agricultural Water Management, 1995; 27(3-4): 243-257.

[21] Li J S. Modeling crop yield as affected by uniformity of sprinkler irrigation system. Agricultural Water Management, 1998; 38(2): $135-146$. 